\title{
Complications and Neurological Outcome following Intraoperative Aneurysm Rupture in Adult Patients Undergoing Intracranial Aneurysmal Clipping: A Retrospective Study
}

\author{
Nayani Radhakrishna ${ }^{1}$ Ankur Khandelwal ${ }^{2}$ Rajendra Singh Chouhan ${ }^{2}$ Mihir Prakash Pandia ${ }^{2}$ \\ Sourav Burman² Rashmi Rani Mahapatra²
}

\author{
${ }^{1}$ Department of Anaesthesia and Critical Care, Army Hospital \\ Research and Referral, Delhi Cantt, India \\ 2Department of Neuroanaesthesiology and Critical Care, All India \\ Institute of Medical Sciences (AlIMS), New Delhi, India
}

Address for correspondence Rajendra Singh Chouhan, MD, Department of Neuroanaesthesiology and Critical Care, All India Institute of Medical Sciences (AIIMS), CN Centre, Ansari Nagar, New Delhi 110029, India (e-mail: drrajendrasinghchouhan@gmail.com).

J Neurosci Rural Pract 2021;12:382-388.

\author{
Abstract \\ Keywords \\ - aneurysm clipping \\ - complications \\ - intracranial aneurysm \\ - intraoperative \\ aneurysm rupture \\ - Glasgow outcome \\ scale
}

Background Intraoperative aneurysmal rupture (IAR) is a catastrophic complication; however, its impact on neurological outcome is debatable. We studied the effects of IAR on intraoperative and postoperative complications and neurological outcome.

Methods In this retrospective study, adult patients who underwent aneurysmal clipping over a period of 2 years were divided as follows: group R (with IAR) and group $\mathrm{N}$ (without IAR). Various perioperative parameters, intraoperative and postoperative complications were noted. Glasgow outcome scale (GOS) was noted at discharge from hospital and categorized as favorable (GOS IV and V) and unfavorable (GOS I, II and III). Collected data was statistically analyzed. Univariate and multiple logistic regression analyses were performed to identify predictors of IAR. A $p$ value $<0.05$ was considered significant.

Results Thirty-two out of $195(16.41 \%)$ patients suffered IAR, with majority involving anterior communicating artery aneurysm (46.88\%). Duration of temporary clipping $(p<0.001)$, volume of blood loss, and fluid and blood transfusion were significantly more in group R. Postoperatively, significantly more patients in group $R$ developed intracranial hematoma, cerebral infarct, and required prolonged ventilatory support ( $\geq 5$ days). Unfavorable neurological outcome was observed more in group $R$ $(p=0.013)$. In univariate analysis, blood loss $>500 \mathrm{~mL}$, use of colloids, and duration of surgery $>5$ hours were found to be associated with IAR. After multiple logistic regression analysis, only use of colloids and duration of surgery $>5$ hours were the most predictive variables for IAR.

Conclusions IAR is associated with serious intraoperative and postoperative complications and unfavorable neurological outcome.
DOI https://doi.org/

$10.1055 / \mathrm{s}-0041-1724228$

ISSN 0976-3147. (c)2021. Association for Helping Neurosurgical Sick People.

This is an open access article published by Thieme under the terms of the Creative Commons Attribution-NonDerivative-NonCommercial-License, permitting copying and reproduction so long as the original work is given appropriate credit. Contents may not be used for commercial purposes, or adapted, remixed, transformed or built upon. (https://creativecommons.org/licenses/by-nc-nd/4.0/).

Thieme Medical and Scientific Publishers Pvt. Ltd. A-12, 2nd Floor, Sector 2, Noida-201301 UP, India 


\section{Introduction}

Intracranial aneurysmal rupture (IAR) during its obliteration is a well-known and potentially lethal complication with aneurysmal subarachnoid hemorrhage (aSAH). ${ }^{1}$ Incidence of IAR ranges from $2 \%$ to $4.5 \%$ for endovascular techniques and $6.0 \%$ to $61 \%$ for surgical clipping. ${ }^{1-3}$ However, the impact of IAR on neurological outcome of patients undergoing aneurysm clipping is controversial and understudied. Furthermore, there is hardly any data on this important subject among the Indian population.

We conducted this retrospective study to evaluate the effects of IAR on intraoperative and postoperative complications and neurological outcome.

\section{Methods}

After obtaining approval from the Institutional Ethics Committee, data of all patients aged $>18$ years, who underwent aneurysm clipping for aSAH over a span of 2 years were collected. Patients' demographic parameters, clinical and aneurysmal characteristics along with perioperative details were noted. The patients were then divided into two groups based on occurrence of IAR as group $\mathrm{R}$ (with IAR) and group $\mathrm{N}$ (without IAR). Other surgical procedures/interventions performed postoperatively, mechanical ventilation (MV) days, and duration of hospital stay were also noted. Glasgow outcome scale (GOS) grades were noted at the time of discharge from hospital. ${ }^{4}$ GOS grades IV and V were considered "favorable neurological outcome," whereas "unfavorable neurological outcome" included GOS grades I, II and III.

\section{Statistical Analysis}

Statistical analysis was performed using STATA 12.1 (College Stations, Texas, USA). Data are presented as number (\%), mean \pm standard deviation (SD), or median (quartile deviation [QD]) as appropriate. Chi-square and Fischer's exact test (when one or more expected frequencies were less than 5) were used to compare categorical variables and students' " $\mathrm{t}$ " test for continuous variables. Univariate analysis followed by multiple logistic regression analysis was performed to identify risk factors and independent predictors for occurrence of IAR. A $p$ value $<0.05$ was considered significant.

\section{Results}

During the study period, 195 adult patients underwent cerebral aneurysm clipping. IAR occurred in $32(16.41 \%)$ patients. Demographic parameters and preoperative clinical characteristics (except preoperative ventilation) were comparable between the groups (-Table 1). Hunt and Hess' grade II, World Federation of Neurological Surgeons (WFNS) grade I, and Fischer's grade 2 were the most common grades on presentation ( - Table 2). Overall, mean interval between ictus to admission and surgery were $10 \pm 15.3$ and $11.92 \pm 16.12$ days.

Overall, 228 aneurysms were detected on digital subtraction angiography (DSA) of study patients. Locationwise, anterior communicating (ACOM) artery aneurysms were the most common (47.17\%). Both the groups were statistically comparable regarding location of aneurysms (-Table 3). Overall, 28 patients (14.3\%) had multiple aneurysms. Eleven patients $(6.7 \%)$ in group $\mathrm{N}$ had giant aneurysms $(>2.5 \mathrm{~cm})$ compared with 1 patient $(3.1 \%)$ in group

Table 1 Demographic and preoperative parameters along with clinical characteristics of the study patients

\begin{tabular}{|c|c|c|c|c|c|}
\hline \multicolumn{2}{|l|}{ Variable } & $\begin{array}{l}\text { Group N } \\
(n=163)\end{array}$ & $\begin{array}{l}\text { Group R } \\
(n=32)\end{array}$ & $\begin{array}{l}\text { Total } \\
(n=195)\end{array}$ & $p$-Value \\
\hline \multicolumn{2}{|l|}{ Age (years) } & $47.8 \pm 12$ & $52.2 \pm 12.8$ & $48.5 \pm 12.1$ & 0.06 \\
\hline \multicolumn{2}{|l|}{ Gender (male/female) } & $79 / 84$ & $14 / 18$ & $93 / 102$ & 0.62 \\
\hline \multicolumn{2}{|c|}{ Admission GCS, median (QD) } & $13.4(2.7)$ & $13.1(3)$ & $13.3(2.7)$ & 0.55 \\
\hline \multicolumn{2}{|c|}{ Pre-operative ventilation, $n$ (\%) } & $29(17.7)$ & $25(78)$ & $54(95)$ & $<0.05$ \\
\hline \multirow[t]{4}{*}{ Comorbidities, $n(\%)$} & Essential Hypertension & $55(33.7)$ & 14(43.7) & $69(35.4)$ & 0.24 \\
\hline & Diabetes mellitus & $7(4.3)$ & 00 & $7(3.6)$ & 0.23 \\
\hline & $\begin{array}{l}\text { Coronary artery disease } \\
\text { (CAD) }\end{array}$ & 01 & 00 & 01 & \\
\hline & $\begin{array}{l}\text { Chronic obstructive pul- } \\
\text { monary disease (COPD) }\end{array}$ & 00 & 01 & 01 & \\
\hline \multirow[t]{2}{*}{ Hemoglobin (g/dL) } & Mean & $11.9 \pm 1.7$ & $11.7 \pm 1.5$ & $11.8 \pm 1.7$ & 0.61 \\
\hline & $<10 \mathrm{~g} / \mathrm{dL}$ & $18(11)$ & $5(15.6)$ & $23(11.8)$ & 0.61 \\
\hline \multirow{4}{*}{$\begin{array}{l}\text { Admission serum } \\
\text { sodium (mEq/L) }\end{array}$} & Mean & $141.1 \pm 5.8$ & $140.8 \pm 3.9$ & $141.10 \pm 5.51$ & \multirow[t]{4}{*}{0.74} \\
\hline & $135-145$ & $112(68.7)$ & $28(87.5)$ & $140(84.8)$ & \\
\hline & $<135$ & $19(11.6)$ & $2(6.2)$ & $21(10.7)$ & \\
\hline & $>145$ & $32(19.6)$ & $2(6.2)$ & $34(17.4)$ & \\
\hline \multirow{3}{*}{$\begin{array}{l}\text { Time interval } \\
\text { (days) }\end{array}$} & Ictus to admission & $10.5 \pm 16$ & $7.5 \pm 11.4$ & $10 \pm 15.3$ & 0.72 \\
\hline & Ictus to surgery & $12.4 \pm 16.7$ & $9.5 \pm 12.5$ & $11.9 \pm 16.1$ & 0.62 \\
\hline & Admission to surgery & $1.9 \pm 1.6$ & $1.9 \pm 1.7$ & $1.9 \pm 1.6$ & 0.63 \\
\hline
\end{tabular}

Abbreviations: CAD, coronary artery disease; COPD, chronic obstructive pulmonary disorder; GCS, Glasgow Coma Scale; QD, quartile deviation. 
Table 2 Distribution of the study patients in various subarachnoid hemorrhage grades

\begin{tabular}{|c|c|c|c|c|c|}
\hline Grading system & Grades & $\begin{array}{l}\text { Group N } \\
(n=163)\end{array}$ & $\begin{array}{l}\text { Group R } \\
(n=32)\end{array}$ & $\begin{array}{l}\text { Total } \\
(n=195)\end{array}$ & $p$-Value \\
\hline \multirow[t]{5}{*}{ Hunt and Hess' classification } & 1 & $29(17.8)$ & $6(18.7)$ & 35 (17.9) & \multirow[t]{5}{*}{0.64} \\
\hline & II & $73(44.8)$ & $11(34.4)$ & $84(43.1)$ & \\
\hline & III & $30(18.4)$ & $6(18.7)$ & $36(18.4)$ & \\
\hline & IV & $20(12.3)$ & 7 (21.9) & $27(13.8)$ & \\
\hline & V & $11(6.7)$ & $2(6.2)$ & $13(6.6)$ & \\
\hline \multirow[t]{5}{*}{ World Federation of Neurological Surgeons Scale } & 1 & $90(55.2)$ & $17(53.1)$ & $107(54.8)$ & \multirow[t]{5}{*}{0.92} \\
\hline & II & $28(17.2)$ & $5(15.6)$ & $33(16.9)$ & \\
\hline & III & $9(5.5)$ & $3(9.4)$ & $12(6.1)$ & \\
\hline & IV & $28(17.2)$ & $6(18.7)$ & $34(17.4)$ & \\
\hline & V & $8(4.9)$ & $1(3.1)$ & $9(4.2)$ & \\
\hline \multirow[t]{4}{*}{ Fischer's Grading Scale } & 1 & $11(6.7)$ & $1(3.1)$ & $12(6.5)$ & \multirow[t]{4}{*}{0.69} \\
\hline & ॥ & $89(54.6)$ & $16(50)$ & $105(53.8)$ & \\
\hline & III & $12(7.3)$ & $2(6.2)$ & $14(7.2)$ & \\
\hline & IV & $51(31.3)$ & $13(40.6)$ & $64(32.8)$ & \\
\hline
\end{tabular}

Note: All parameters are expressed in $n(\%)$

Table 3 Aneurysmal Characteristic and timing of surgery after ictus in the study

\begin{tabular}{|c|c|c|c|c|c|}
\hline \multicolumn{2}{|c|}{ Characteristics of aneurysm } & $\begin{array}{l}\text { Group N } \\
n=163\end{array}$ & $\begin{array}{l}\text { Group R } \\
n=32\end{array}$ & $\begin{array}{l}\text { Total } \\
n=195\end{array}$ & $p$-Value \\
\hline \multirow[t]{6}{*}{ Location } & ACOM & $77(47.2)$ & $15(46.9)$ & $92(47.2)$ & 0.97 \\
\hline & ACA & $11(6.7)$ & $3(9.4)$ & $14(7.2)$ & 0.59 \\
\hline & MCA & $43(26.4)$ & $11(34.4)$ & $54(27.7)$ & 0.35 \\
\hline & PCOM artery & $28(17.2)$ & $6(18.7)$ & $34(17.4)$ & 0.83 \\
\hline & ICA & $27(16.5)$ & $6(18.7)$ & $33(16.9)$ & 0.76 \\
\hline & Multiple aneurysms & $22(13.5)$ & $6(18.7)$ & $28(14.3)$ & 0.62 \\
\hline \multicolumn{2}{|c|}{ Giant aneurysm (size > $2.5 \mathrm{~cm}$ ) } & $11(6.7)$ & $1(3.1)$ & $12(6.1)$ & 0.43 \\
\hline \multirow[t]{3}{*}{ Timing of surgery } & Early (within 72 hours) & $49(30)$ & $10(31.2)$ & $59(30.2)$ & \\
\hline & $\begin{array}{l}\text { Intermediate } \\
\text { (4 to } 10 \text { days) }\end{array}$ & $62(38)$ & $13(40.6)$ & $75(38.5)$ & \\
\hline & Late (> 10 days) & $52(31.9)$ & $9(28.1)$ & $61(31.3)$ & \\
\hline
\end{tabular}

Abbreviations: ACA, anterior cerebral artery; ACOM, anterior communicating artery; ICA, internal carotid artery; MCA, middle cerebral artery; PCOM, posterior communicating.

Note: All parameters are expressed in $n(\%)$

R. Aneurysms in 59, 75 and 61 patients were clipped within 3 days (early surgery), 4 to 10 days (intermediate surgery) and $>10$ days (late surgery), respectively, after the ictus. Distribution of patients in the two groups was comparable across these categories.

All patients underwent craniotomy and aneurysm clipping under standard general anesthetic technique in supine position using either nitrous oxide/air and volatile anesthetic agent (sevoflurane/desflurane) or total intravenous anesthesia (TIVA) with propofol, supplemented with fentanyl and muscle relaxant. Although, all patients received 0.5 to $1.0 \mathrm{~g} / \mathrm{kg}$ mannitol, starting at skin incision, brain bulge was found after craniotomy in 20 and 84 patients in group $\mathrm{R}$ and $\mathrm{N}$, respectively, requiring additional measures to achieve slack brain. In group N, temporary clip was applied in 145 (88.9\%) patients compared with 31 (96.8\%) patients in group R. Total duration of temporary clip application was significantly longer in group $\mathrm{R}$ against group $\mathrm{N}$ patients $(p<0.001)$.

Blood loss was significantly more in group R (992.18 \pm 505.79 vs. $405.82 \pm 232.03 \mathrm{~mL}$ ), requiring more crystalloid solution ( $4506.25 \pm 1025.78$ vs. $3733.13 \pm 976.08 \mathrm{~mL}$ ) administration and more patients to receive blood transfusion (78.12\% vs. $15.33 \%$ ) in this group (-Table 4). Additionally, group R patients also had significantly more colloids administration. Majority of the IAR occurred in patients with ACOM aneurysm (46.88\%), followed by middle cerebral artery aneurysms, and posterior communicating (PCOM) artery aneurysms. As per stage of surgery, 9 (28.25\%) IARs occurred during dissection phase of surgery and remaining 23 (71.87\%) IARs occurred during clip application on aneurysm. 
Table 4 Intraoperative parameters in the study patients

\begin{tabular}{|c|c|c|c|c|c|}
\hline \multicolumn{2}{|l|}{ Parameter } & $\begin{array}{l}\text { Group N } \\
(n=163)\end{array}$ & $\begin{array}{l}\text { Group R } \\
(n=32)\end{array}$ & $\begin{array}{l}\text { Total } \\
(n=195)\end{array}$ & $p$-Value \\
\hline \multicolumn{2}{|l|}{ Tense brain, $n(\%)$} & $84(51.5)$ & $20(62.5)$ & $104(53.3)$ & 0.33 \\
\hline \multirow{2}{*}{$\begin{array}{l}\text { Intravenous fluid-administered } \\
\text { (mean } \pm \text { SD) }\end{array}$} & Crystalloid (mL) & $3733 \pm 976$ & $4506 \pm 1025.7$ & $3860 \pm 1022.8$ & $<0.001$ \\
\hline & Colloid (mL) & $588 \pm 196.4$ & $750 \pm 474.3$ & $680 \pm 320.2$ & $<0.001$ \\
\hline \multicolumn{2}{|l|}{$\begin{array}{l}\text { Urine output (mL) } \\
\text { (mean } \pm \text { SD) }\end{array}$} & $1219 \pm 690.4$ & $1240 \pm 690.4$ & $1240 \pm 690.4$ & 0.32 \\
\hline \multicolumn{2}{|l|}{$\begin{array}{l}\text { Blood loss }(\mathrm{mL}) \\
(\text { mean } \pm \text { SD) }\end{array}$} & $405 \pm 232$ & $992 \pm 505.7$ & $502 \pm 365$ & $<0.001$ \\
\hline \multicolumn{2}{|l|}{ Blood loss > 500 mL, $n(\%)$} & $44(26.9)$ & $28(87.0)$ & $72(36.2)$ & $<0.001$ \\
\hline \multicolumn{2}{|c|}{ Patients receiving blood transfusion, $n(\%)$} & $25(15.3)$ & $25(78.1)$ & $50(25.6)$ & $<0.001$ \\
\hline \multicolumn{2}{|l|}{$\begin{array}{l}\text { Temporary clip time (min) } \\
(\text { mean } \pm \text { SD) }\end{array}$} & $7.4 \pm 6.8$ & $14.4 \pm 7.9$ & $8.63 \pm 7.4$ & $<0.001$ \\
\hline \multicolumn{2}{|l|}{$\begin{array}{l}\text { Duration of surgery (Hours) } \\
\text { (mean } \pm \text { SD) }\end{array}$} & $5.1 \pm 1.01$ & $5.6 \pm 1.15$ & $5.2 \pm 1.05$ & $<0.05$ \\
\hline \multicolumn{2}{|c|}{ Tracheal extubation in operation theater, $n(\%)$} & $66(40.4)$ & $4(12.5)$ & 70 (35.9) & $<0.05$ \\
\hline
\end{tabular}

Table 5 Various postoperative variables and complications in the study group

\begin{tabular}{|l|l|l|l|l|}
\hline Variable & $\begin{array}{l}\text { Group N } \\
(\boldsymbol{n}=163)\end{array}$ & $\begin{array}{l}\text { Group R } \\
(\boldsymbol{n}=32)\end{array}$ & $\begin{array}{l}\text { Total } \\
(\boldsymbol{n}=195)\end{array}$ \\
\hline Hematoma & $9(5.5)$ & $7(21.8)$ & $16(8.2)$ & 0.002 \\
\hline Hydrocephalus & $16(9.8)$ & $2(6.2)$ & $18(9.2)$ & 0.12 \\
\hline Cerebral vasospasm & $36(22.0)$ & $8(25)$ & $44(22.5)$ & 0.71 \\
\hline Cerebral infarct & $33(20.2)$ & $16(50)$ & $49(25.1)$ & 0.002 \\
\hline Decompressive craniectomy & $10(6.1)$ & $10(31.3)$ & $20(10.3)$ & $<0.001$ \\
\hline Hemiparesis & $51(31.2)$ & $16(50)$ & $67(34.3)$ & 0.04 \\
\hline Meningitis & $10(6.1)$ & $0(0)$ & $10(5.1)$ & 0.15 \\
\hline Sepsis & $32(19.6)$ & $8(25)$ & $40(20.5)$ & 0.49 \\
\hline Pneumonia & $25(15.3)$ & $7(21.8)$ & $32(16.4)$ & 0.36 \\
\hline Renal failure & $7(4.2)$ & $2(6.2)$ & $9(4.6)$ & 0.6 \\
\hline Hyponatremia & $20(12.2)$ & $6(18.7)$ & $26(13.3)$ & 0.32 \\
\hline Hypernatremia & $9(5.5)$ & $3(9.3)$ & $12(6.1)$ & 0.40 \\
\hline Postoperative ventilation & $97(59.5)$ & $27(84.4)$ & $124(63.6)$ & $<0.05$ \\
\hline Prolonged Ventilation $>5$ days) & $45(27.6)$ & $16(50)$ & $61(31.3)$ & 0.01 \\
\hline Tracheostomy & $33(20.2)$ & $14(43.7)$ & $47(24.1)$ & 0.00 \\
\hline
\end{tabular}

Note: All parameters are expressed in $n(\%)$

Duration of surgery was longer in group $\mathrm{R}(p<0.05)$. Significantly, more patients ( $40.49 \%$ vs. $12.50 \%$ ) were extubated at the end of the procedure in group N. Postoperatively, significantly, more patients in group R developed intracranial hematoma and required surgical evacuation (-Table 5). Half of the total patients (50\%), who suffered IAR, developed cerebral infarct compared with $33(20.24 \%)$ patients in group $\mathrm{N}(p$ $=0.002)$. Significantly, more patients (31.3\% vs. $6.1 \%)$ in group $\mathrm{R}$ required decompressive craniectomy. Other important postoperative complications included cerebral vasospasm (diagnosed by transcranial Doppler and/or angiography), hydrocephalus, meningitis, pneumonia, sepsis, dysnatremia and renal failure, which were statistically comparable between the study groups. Duration of MV was significantly more in group R patients. Overall, median postoperative hospital stay was 10 (range 01-142) days, and total hospital stay was comparable between the two groups.

At discharge from hospital, 87 patients (53.37\%) of group $\mathrm{N}$ and 11 (34.37\%) patients in group R had outcome of GOS $\mathrm{V}$ (-Table 6). Overall, there were 35 (17.94\%) fatalities (GOS I), of which 10 (31.2\%) were in group R and 25 (15.3\%) in group N. Across various GOS grades, distribution of patients in the two groups was statistically comparable. Majority of patients $(60.74 \%)$ in group $\mathrm{N}$ had favorable neurological outcome (GOS V and IV) compared with $37.50 \%$ patients in group $\mathrm{R}$. Unfavorable neurological outcome occurred in $64(39.26 \%)$ and $20(62.5 \%)$ patients in group $\mathrm{N}$ and $\mathrm{R}$, respectively $(p=0.013)$. On univariate analysis, none of 
Table 6 Distribution of patients in various GOS grades and neurological outcome

\begin{tabular}{|l|l|l|l|l|l|}
\hline \multicolumn{2}{|l|}{ Neurological outcome } & $\begin{array}{l}\text { Group N } \\
(n=163)\end{array}$ & $\begin{array}{l}\text { Group R } \\
(\boldsymbol{n}=32)\end{array}$ & $\begin{array}{l}\text { Total } \\
(\boldsymbol{n}=195)\end{array}$ & $p$-Value \\
\hline \multirow{4}{*}{ GOS } & V & $87(53.3)$ & $11(34.3)$ & $98(50.2)$ & 0.12 \\
\cline { 2 - 6 } & IV & $12(7.3)$ & $1(3.1)$ & $13(6.7)$ \\
\cline { 2 - 6 } & III & $30(18.4)$ & $8(25)$ & $38(19.4)$ \\
\cline { 2 - 6 } & II & $9(5.5)$ & $2(6.2)$ & $11(5.6)$ \\
\cline { 2 - 6 } & I & $25(15.3)$ & $10(31.2)$ & $35(17.9)$ \\
\cline { 2 - 6 } & Favorable outcome (GOS IV, V) & $99(60.7)$ & $12(37.5)$ & $111(56.9)$ & 0.01 \\
\cline { 2 - 6 } & Unfavorable outcome (GOS I, II, III) & $64(39.2)$ & $20(62.5)$ & $84(43)$ & \\
\hline
\end{tabular}

Abbreviation: GOS, Glasgow Outcome Scale.

Note: All parameters are expressed in $n(\%)$

the demographic or preoperative variables were related to occurrence of IAR, but intraoperative blood loss $>500 \mathrm{~mL}$, use of colloids and duration of surgery $>5$ hours had significant association with IAR. However, after multiple logistic regression analysis, only intraoperative use of colloids and duration of surgery $>5$ hours were found to be the most predictive variables for IAR.

\section{Discussion}

Despite IAR being a relatively frequent and potentially catastrophic complication in patients undergoing surgical clipping following aSAH, unfortunately, there is not much substantive evidence on factors leading to IAR and its influence on neurological outcome of these patients. In this study, patients in group $\mathrm{R}$ had more intraoperative and postoperative complications and unfavorable neurological outcome.

Although earlier studies reported higher IAR rates in patients undergoing aneurysm clipping following aSAH, we found IAR rate of $16.41 \%$, which is comparable to recent repo rts. ${ }^{5,6,7-9}$ Geographical variations, inclusion/exclusion of minor bleeds during clip application, improvement in microsurgical techniques, neurosurgeons' experience, and anesthetic technique might be causal to this wide variation in IAR incidence.

Lakicevic and colleagues reported higher incidence of IAR in male patients ( $20.38 \%$ vs. 10.14$)$, but no other study found such results. ${ }^{10}$ In our study, IAR rates were comparable between male and female patients (15.05\% vs. $17.64 \%$ ).

Amongst the various risk factors, hypertension is the most important for formation and rupture of cerebral aneurysm. Hypertension leads to increase in the transmural pressure gradient across the cerebral aneurysm, increasing risk of rupture in poorly controlled hypertensive patients, ${ }^{11}$ however, IAR may also occur in patients with well-controlled hypertension. In our study, both hypertensive and normotensive patients had comparable IAR rates ( $20.28 \%$ vs. $14.28 \%$ ). Diabetes mellitus is also suggested to increase risk of aneurysm rupture. ${ }^{12,13}$ Although all patients in our study cohort suffered aSAH, it is interesting that all seven diabetic patients were in group N. Elijovich and coworkers suggested that comorbidities like coronary artery disease (CAD) and chronic obstructive pulmonary disease (COPD) are linked with increased risk of IAR, probably due to altered vessel wall strength, caused by associated risk factors such as smoking and hypertension. ${ }^{1}$ However, a very small number of patients in our study (we had only one patient each with CAD and COPD) precludes us to make any observation on it.

Although Le Roux et al described similar incidence of IAR in good and poor grade SAH patients, ${ }^{14}$ in our study, majority of patients suffering IAR belonged to good grades (Hunt and Hess'-71.87\% and WFNS-78.12\%), probably due to larger proportion of good grade patients in the study cohort (Hunt and Hess'-79.4\% and WFNS-77.8\%). However, Fischer's grading had almost similar distribution of good and poor grades (53.12\% vs. $46.87 \%$ ) in group R.

Relationship between location of aneurysm and IAR is also not clear. Anterior cerebral artery, ACOM artery, posterior inferior cerebellar artery, and PCOM artery aneurysms have been reported to have higher IAR rates in different studies. ${ }^{15,16}$ However, Sundt et al did not find relation between location of aneurysm and IAR, ${ }^{17}$ and our study also found similar results.

Size of aneurysm seems to substantially affect rate of IAR, with smaller aneurysms being less vulnerable. ${ }^{18}$ In our study, 12 patients (6.15\%) had giant aneurysm, out of which only one patient suffered IAR. However, our data lacked in differentiation between small/large size; therefore, based on available data, we cannot make any substantial statement on this issue.

Recently, Hsu and coworkers reported experience of the surgeon and preoperative Glasgow coma scale (GCS) score of the patients as independent predictors of major intraoperative rupture..$^{19}$ In our study, we could not analyze role of surgeons' experience in IAR because of inadequate data; however, preoperative GCS scores were comparable between the study groups.

Early surgical intervention is preferred to minimize risk of rebleeding which is very high in initial few days after aSAH and is considered a neurosurgical emergency. However, less than half (42.56\%) of our study patients got admitted to the hospital within 3 days of ictus (early surgery). Although controversial, early surgery after SAH is reported to be associated with higher IAR rates. Schramm and Cedzich reported $40.2 \%$ incidence of IAR in early surgery group against $20.7 \%$ in surgery after 72 hours of SAH. ${ }^{15}$ Lakicevic et al found $58.23 \%$ IAR if surgery was undertaken within 10 days after SAH. ${ }^{10}$ However, Kassell and associates did not find a difference in IAR in early 
versus late surgery. ${ }^{6}$ Similarly, we also found comparable IAR rates in the early and late surgery group. However, if early and intermediate surgery groups are combined, then $71.87 \%$ IAR falls into this group against late surgery group. This higher risk is due to higher fragility of blood clot sealing the original rupture site, which is further increased by technical difficulties in surgical dissection in early surgery group because of a tight brain. Kassell et al noted a tight brain in nearly half of the patients undergoing surgery on day zero or one after SAH compared with $20 \%$ patients undergoing surgery $\geq 10$ days after aSAH. ${ }^{6}$ Frequency of finding a tense brain decreased progressively $(67.79 \%, 56 \%$ and $36.6 \%$ ) for early, intermediate and late surgery groups in our study. Heuer and colleagues noted elevated intracranial pressure (>20 mm $\mathrm{Hg}$ ) in $48.7 \%$ of good (I, II, III) and 63.6\% poor (IV, V) Hunt and Hess' grade patients during their hospital course and found intraoperative cerebral swelling, which is significantly associated with raised intracranial pressure. ${ }^{20}$ We found a tense brain in 70 patients (45.16\%) in good and 35 patients ( $87.50 \%$ ) in poor Hunt and Hess' grades, however, intracranial pressure was not measured in our study. About one-fifth (20\%) of these patients suffered IAR.

IAR has been classically described by way of three stages during the surgery. ${ }^{21,22}$ In our study, while 9 IARs (28.25\%) occurred during dissection phase of surgery, the remaining 23 (71.87\%) IARs occurred during clip application on the aneurysm. Rupture during dissection of aneurysm can occur because of "tugging" on tissues adherent to the aneurysm or by direct tearing or puncture of the aneurysm by dissecting instruments.

Fridriksson and colleagues reported longer temporary clipping time in cases of IAR compared with when temporary clip is applied to facilitate dissection of aneurysm..$^{23}$ There is difference between "voluntary" versus almost "compulsory" indication of temporary clipping in these two surgical situations. In our study, too, temporary clipping time was significantly more in group $\mathrm{R}$ patients. Temporary clip application on the feeding vessels substantially decreases perfusion to the dependent areas, imposing ischemic risk; however, its threshold limits are controversial. ${ }^{24,25}$ Various physiological and pharmacological cerebral protective measures have been studied for decreasing this risk; however, they were not found to be beneficial. ${ }^{26-28}$ The key to successful management during major rupture are surgeons' experience and skill in controlling torrential bleeding and aneurysm clipping in addition to a vigilant neuroanesthesiologist maintaining adequate cerebral perfusion with rapid infusion of intravenous fluids, blood transfusion and use of vasopressors, if needed. Recently, adenosine-induced cardiac arrest has been reported with good results in face of IAR, but it needs to be planned in advance and have certain contraindications. ${ }^{29}$ In our study, adenosine was not used in any case of IAR.

Postoperatively, more patients in group $\mathrm{R}$ developed intracranial hematoma requiring surgical evacuation, and cerebral infarct requiring decompressive craniectomy and hemiparesis. All these complications led to prolonged duration of MV. Although Ramaiah and colleagues reported higher incidence of cerebral vasospasm in patients afflicted with IAR (33.8\% vs. $19.7 \%),{ }^{9}$ Sheth and coworkers did not find such influence of IAR. ${ }^{30}$ We also found similar incidence of cerebral vasospasm between the study groups.

Whether occurrence of IAR affects neurological outcome of patients undergoing aneurysm clipping following aSAH is controversial. Although Schramm and Cedzich suggested that, in experienced hands, IAR is not necessarily associated with increased risk of unfavorable outcome, ${ }^{15}$ Lin et al reported poor outcome in major intraoperative rupture. ${ }^{8}$ Ramaiah and colleagues also did not find significant impact of IAR on neurological outcome. ${ }^{9}$ However, in our study, unfavorable outcome (GOS I, II and II) occurred in significantly more patients in group R (62.50\% vs. $39.26 \%)$. In other words, more patients who did not suffer IAR had favorable neurological outcome.

Our study does have some limitations, for example, retrospective study design, no differentiation of major and minor aneurysm ruptures, no data about surgical experience, and no posterior circulation aneurysm. Further large studies across major centers, analyzing all important factors as discussed, are required to elucidate risk factors for IAR and its effect on neurological outcome of these patients precisely.

\section{Conclusions}

Our study focused on evaluating impact of IAR during aneurysmal clipping on various intraoperative and postoperative complications and neurological outcome of these patients. We found significantly more blood loss, intravenous fluid administration, blood transfusion, and longer temporary clipping due to this serious complication. Our data demonstrates that patients afflicted with IAR develop several serious complications and have worse neurological outcome. However, more large studies are needed to validate these results.

\section{Funding \\ None. \\ Conflict of Interest \\ None declared.}

\section{References}

1 Elijovich L, Higashida RT, Lawton MT, Duckwiler G, Giannotta S, Johnston SC; Cerebral Aneurysm Rerupture After Treatment (CARAT) Investigators. Predictors and outcomes of intraprocedural rupture in patients treated for ruptured intracranial aneurysms: the CARAT study. Stroke 2008;39(5):1501-1506

2 Grasso G, Perra G. Surgical management of ruptured small cerebral aneurysm: Outcome and surgical notes. Surg Neurol Int 2015;6:185

3 Gupta MM, Bithal PK, Dash HH, Chaturvedi A, Prabhakar H. Clinical outcome of intracranial aneurysms: a retrospective comparison between endovascular coiling and neurosurgical clipping. Indian J Anaesth 2008;52:63

4 Jennett B, Bond M. Assessment of outcome after severe brain damage. Lancet 1975;1(7905) :480-484

5 Pertuiset B, Intraoperative aneurysmal rupture and reduction by coagulation of the sac. In: Pia HW, Langmaid C, Zierski J, eds. Cerebral Aneurysms - Advances in Diagnosis and Therapy. Berlin: Springer-Verlag; 1979: 398-401 
6 Kassell NF, Torner JC, Haley ECJr, Jane JA, Adams HP, Kongable GL. The international cooperative study on the timing of aneurysm surgery. Part 1: overall management results. J Neurosurg 1990;73(1):18-36

7 Houkin K, Kuroda S, Takahashi A, et al. Intra-operative premature rupture of the cerebral aneurysms. Analysis of the causes and management. Acta Neurochir (Wien) 1999;141(12):1255-1263

8 Lin TK, Hsieh TC, Tsai HC, Lu YJ, Lin CL, Huang YC. Factors associated with poor outcome in patients with major intraoperative rupture of intracranial aneurysm. Acta Neurol Taiwan 2013;22(3):106-111

9 Ramaiah VK, Chouhan RS, Radhakrishnan M, Gupta MM, Bithal PK. Effect of rupture of intracranial aneurysm on neurological outcome. Anesthesiology 2007;107:A1062

10 Lakićević N, Vujotić L, Radulović D, Cvrkota I, Samardžić M. Factors affecting intraoperative rupture of intracranial aneurysms. Turk Neurosurg 2015;25(6):858-885

11 Chowdhury T, Petropolis A, Wilkinson M, Schaller B, Sandu N, Cappellani RB. Controversies in the anesthetic management of intraoperative rupture of intracranial aneurysm. Anesthesiol Res Pract 2014;2014:595837

12 Clarke M. Systematic review of reviews of risk factors for intracranial aneurysms. Neuroradiology 2008;50(8):653-664

13 Inagawa $T$. Risk factors for the formation and rupture of intracranial saccular aneurysms in Shimane, Japan. World Neurosurg 2010;73(3):155-164, discussion e23

14 Le Roux PD, Elliot JP, Newell DW, Grady MS, Winn HR. The incidence of surgical complications is similar in good and poor grade patients undergoing repair of ruptured anterior circulation aneurysms: a retrospective review of 355 patients. Neurosurgery 1996;38(5):887-893, discussion 893-895

15 Schramm J, Cedzich C. Outcome and management of intraoperative aneurysm rupture. Surg Neurol 1993;40(1):26-30

16 Leipzig TJ, Morgan J, Horner TG, Payner T, Redelman K, Johnson CS. Analysis of intraoperative rupture in the surgical treatment of 1694 saccular aneurysms. Neurosurgery 2005;56(3):455468, discussion 455-468

17 Sundt TM Jr, Kobayashi S, Fode NC, Whisnant JP. Results and complications of surgical management of 809 intracranial aneurysms in 722 cases. Related and unrelated to grade of patient, type of aneurysm, and timing of surgery. J Neurosurg 1982;56(6):753-765

18 Sluzewski M, Bosch JA, van Rooij WJ, Nijssen PC, Wijnalda D. Rupture of intracranial aneurysms during treatment with Guglielmi detachable coils: incidence, outcome, and risk factors. J Neurosurg 2001;94(2):238-240

19 Hsu CE, Lin TK, Lee MH, et al. The impact of surgical experience on major intraoperative aneurysm rupture and their consequences on outcome: a multivariate analysis of 538 microsurgical clipping cases. PLoS One 2016;11(3):e0151805

20 Heuer GG, Smith MJ, Elliott JP, Winn HR, LeRoux PD. Relationship between intracranial pressure and other clinical variables in patients with aneurysmal subarachnoid hemorrhage. J Neurosurg 2004;101(3):408-416

21 Batjer H, Samson D. Intraoperative aneurysmal rupture: incidence, outcome, and suggestions for surgical management. Neurosurgery 1986;18(6):701-707

22 Tsementzis SA, Hitchcock ER. Outcome from "rescue clipping" of ruptured intracranial aneurysms during induction anaesthesia and endotracheal intubation. J Neurol Neurosurg Psychiatry 1985;48(2):160-163

23 Fridriksson S, Säveland $\mathrm{H}$, Jakobsson KE, et al. Intraoperative complications in aneurysm surgery: a prospective national study. J Neurosurg 2002;96(3):515-522

24 Ogilvy CS, Carter BS, Kaplan S, Rich C, Crowell RM. Temporary vessel occlusion for aneurysm surgery: risk factors for stroke in patients protected by induced hypothermia and hypertension and intravenous mannitol administration. J Neurosurg 1996;84(5):785-791

25 Dhandapani S, Pal SS, Gupta SK, Mohindra S, Chhabra R, Malhotra SK. Does the impact of elective temporary clipping on intraoperative rupture really influence neurological outcome after surgery for ruptured anterior circulation aneurysms?-A prospective multivariate study. Acta Neurochir (Wien) 2013;155(2):237-246

26 Mahajan C, Chouhan RS, Rath GP, et al. Effect of intraoperative brain protection with propofol on postoperative cognition in patients undergoing temporary clipping during intracranial aneurysm surgery. Neurol India 2014;62(3):262-268

27 Bidkar PU, Chouhan RS, Dash HH, Prabhakar H, Wilma D, Silvia CR. Thiopentone and propofol for brain protection during temporary clipping in intracranial aneurysm surgery: A preliminary comparative surgery. Int J Chem Pharmaceut Res 2013;2(5):123-134

28 Todd MM, Hindman BJ, Clarke WR, Torner JC; Intraoperative Hypothermia for Aneurysm Surgery Trial (IHAST) Investigators. Mild intraoperative hypothermia during surgery for intracranial aneurysm. N Engl J Med 2005;352(2):135-145

29 Luostarinen T, Takala RS, Niemi TT, et al. Adenosine-induced cardiac arrest during intraoperative cerebral aneurysm rupture. World Neurosurg 2010;73(2):79-83, discussion e9

30 Sheth SA, Hausrath D, Numis AL, Lawton MT, Josephson SA. Intraoperative rerupture during surgical treatment of aneurysmal subarachnoid hemorrhage is not associated with an increased risk of vasospasm. J Neurosurg 2014;120(2):409-414 